\title{
Original article Effect of the time of cold maceration on the evolution of phenolic
compounds and colour of Syrah wines elaborated in warm climate
}

\author{
María Jesús Cejudo-Bastante, ${ }^{1}$ Belén Gordillo, ${ }^{1}$ Dolores Hernanz, ${ }^{2}$ María Luisa Escudero-Gilete, ${ }^{1}$ \\ Maria Lourdes González-Miret ${ }^{1}$ \& Francisco J. Heredia ${ }^{1}$ * \\ 1 Food Colour and Quality Laboratory, Department of Nutrition and Food Science, Facultad de Farmacia, Universidad de Sevilla, 41012 \\ Sevilla, Spain \\ 2 Department of Analytical Chemistry, Facultad de Farmacia, Universidad de Sevilla, 41012 Sevilla, Spain
}

(Received 21 October 2013; Accepted in revised form 22 January 2014)

Summary The effect of different cold maceration times on Syrah red wines from warm climate has been evaluated. Differential colorimetry and tristimulus colorimetry were applied to colour data at different points of the vinification stage. Virtually, all the phenolic compounds showed significantly higher content in cold macerated wines, even more when longer contact time was used. Long cold macerated (LCM) wines had the significantly $(P<0.05)$ highest chroma values $\left(C^{*}{ }_{a b}\right)$ and lowest of lightness $\left(L^{*}\right)$ and hue $\left(h_{a b}\right)$. Unexpectedly, wines submitted to short-time cold maceration (SCM) presented the lowest chroma values, even significantly inferior to that observed in traditional macerated (TM) wines. Moreover, colour changes $\left(\Delta E^{*}{ }_{a b}\right)$ between TM and SCM were mainly quantitative $\left(\% \Delta^{2} L\right.$ and $\left.\% \Delta^{2} C\right)$, whereas they were also qualitative when compared TM with LCM $\left(\% \Delta^{2} C\right.$ and $\left.\% \Delta^{2} H\right)$. Cold maceration in warm climates characterised by common colour losses must be carefully employed because undesirable consequences on colour may occur.

Keywords Cold maceration, colour, differential colorimetry, polyphenolic compounds, Syrah red wines, warm climate.

\section{Introduction}

Nowadays, the colour of wine and its stabilisation over the time are the most important factors that directly affect on the acceptability by consumers. They considerably value red wines with an intense colour and hue, mainly due to the transfer of phenolic compounds from grape skins (mainly anthocyanins and other noncoloured such as flavonols) to the grape must (Monagas $\&$ Bartolomé, 2009). In this quest for colour stabilisation, numerous winemaking techniques have been used. Among them, cryomaceration (also called cold soak or cold maceration) is a widely used technique among winemakers. As is well known, this practice consists of keeping the crushed grapes atlow temperatures $\left(5-15^{\circ} \mathrm{C}\right)$ for one to several weeks along the prefermentative maceration stage. The application of low temperatures in an aqueous medium provokes the rupture of the grape skins, spreading a higher amount of pigments, tannins and aromas (Goumy et al., 1996). As a consequence of the low temperatures, the beginning of the

\footnotetext{
*Correspondent: Fax: + 34954556110 ;

e-mail: heredia@us.es
}

alcoholic fermentation is delayed. When cold maceration finished, the temperature is increased (around 20-25 ${ }^{\circ} \mathrm{C}$ ) and the alcoholic fermentation starts. The removal of the skins occurs a few days after, when alcoholic fermentation is almost finished.

In warm regions, the stressful climate conditions make difficult to produce high-quality red wines characterised by a high and stable colour. This fact stems from the high temperatures at which vineyard has normally underwent, not coinciding both phenolic and technology maturity of the grapes at the moment of harvesting (Mori et al., 2005; López et al., 2007). Thus, pulps and skins have reached their optimal maturity (high sugar contents in pulp and the formation of the final dye of red skins that begins at the véraison until ripening) while seeds remained normally unripened. As a consequence, the amount of pigments and cofactors (mainly provided by the ripened seeds) is low and the colour does not stabilise correctly (Boulton, 2001). Therefore, after several months of storage, colour fades.

Worldwide, cold maceration has been widely used in several vinicultural zones, with different results. On the one hand, positive effects were observed in different 
Italian and Spanish grape varieties and locations by an increase in the content of anthocyanins and darker wines (Parenti et al., 2004; Álvarez et al., 2006; GilMuñoz et al., 2009; De Santis \& Frangipane, 2010; Busse-Valverde et al., 2011; Gambacorta et al., 2011; Ortega-Heras et al., 2012).On the other hand, detrimental effects or no substantial improvement in this regard was also reported (Feuillat, 1993, 1996; Heatherbell et al., 1996; Pérez-Lamela et al., 2007; González-Neves et al., 2010, 2012; Soto-Vázquez et al., 2010). In warm climate winemaking where common losses of colour occur, our research group has developed several scientific researches on this matter. Thus, Gómez-Míguez et al. (2007) studied the evolution of colour and anthocyan in composition of Syrah wines during cold maceration, demonstrating that it was a useful technique to increase the extraction of anthocyanins and to obtain darker and less brown wines. Because colour is not only due to free monomeric anthocyanins, Gordillo et al. (2010) proved that the new pigments formed during copigmentation reactions also increased in cold macerated Tempranillo red wines, thus increasing the stabilisation of the colour. Moreover, Heredia et al. (2010) obtained also positive results, resulting in wines with higher values of chroma and red-bluish hues. In spite of the advances in this respect, it is needed to deepen how to improve the colour stabilisation of wines by cold maceration application (for instance, by means of the study of important factors such as length or temperature).

Therefore, the aim of this research was based on the knowledge of the effects of the application of different cold maceration times, barely reported, on the phenolic composition and the chromatic characteristics, compared with a traditionally elaborated red wine. The study was performed on a Syrah red wines, and our interest was focused on several perspectives poorly reported in conjunction with the Andalusia warm climate. In addition, the evolution of the aforementioned parameters during several points of vinification was followed, which is also scarcely reported in that kind of wines and winemaking zone. The usefulness of differential colorimetry to evaluate the changes induced by the cold maceration technique was also assessed.

\section{Materials and methods}

\section{Wine making}

Around $9000 \mathrm{Kg}$ of Vitis vinifera cv. Syrah grapes grown in an experimental vineyard located in 'Condado de Huelva' Designation of Origin (South-Western Spain) was harvested with a desiderable maturity (21.2 ${ }^{\circ}$ Brix) and in good sanitary conditions. The grapes were destemmed and crushed, and the musts were distributed into nine stainless steel tanks of $1000 \mathrm{~L}$ of capacity. Potassium metabisulfite $(50 \mathrm{~g} / 100 \mathrm{Kg}$ of fermentation mash) was added to all experiences. Three different vinifications were carried out.

\section{Traditional winemaking}

Three replicates of control wine were carried out, with on-skin fermentation with indigenous yeasts at controlled temperature $\left(20^{\circ} \mathrm{C}\right)$, as traditional maceration (TM). Fermentation caps were punched down each tank once a day during the on-skin maceration period, which lasted 4 days (fermentative alcoholic maceration).

\section{Cold maceration winemaking}

A prefermentative cold maceration was carried out with temperatures between $5-11^{\circ} \mathrm{C}$. Musts were cooled by addition of carbonic ice into the tanks (Air Liquide, Madrid, Spain). The interval of temperatures from 5 to $11^{\circ} \mathrm{C}$ in tanks was maintained thanks to a cooling water jacket and a thermostatised cold-storage room where tanks were located. Two different periods of time of skin maceration were used at the same temperature: 8 days (SCM, short cold maceration time) and 12 days (LCM, long cold maceration time). After the cold maceration was completed, the temperature of the tanks was risen up to $20^{\circ} \mathrm{C}$ to favour the beginning of the alcoholic fermentation, fact that took place in 2-3 days approximately. Then, 4 days of fermentative alcoholic maceration was applied at this temperature, similar to traditional winemaking. Three replicates of each cold maceration treatment were carried out.

For each nine experiments, barrelling was carried out and the fermentation mash was drawn off to remove the skins and other solid parts. The malolactic fermentation was induced by inoculation of Oenococcus oeni lactic acid bacteria $\left(>10^{10} \mathrm{CFU} O\right.$. oeni per mL, VINIFERM Oe 104, Agrovin, Spain), which occurred after 18 days. Malic and lactic acids were analysed by HPLC to confirm the end of the malolactic fermentation. The wines were then racked and adjusted at the same levels of sulphur dioxide (around 75 and $20 \mathrm{mg} \mathrm{L}^{-1}$ of total and free sulphur dioxide, respectively).

\section{Oenological parameters}

The conventional oenological parameters $(\mathrm{pH}$, total and volatile acidity, free and total $\mathrm{SO}_{2}$, malic and lactic acids and reducing sugars) were performed according to the Official Methods established by European Union (UE, 2003).

\section{Colorimetric measurements}

A Hewlett-Packard UV-Vis HP8452 spectrophotometers (Palo Alto, CA, USA) were used to carry out 
colour measurements. The whole visible spectrum $(380-770 \mathrm{~nm})$ was recorded at constant intervals $(\Delta \lambda=2 \mathrm{~nm})$ using $2 \mathrm{~mm}$ path length glass cells and distilled water as reference. The CIELAB parameters $\left(L^{*}, a^{*}, b^{*}, C^{*}{ }_{a b}\right.$ and $\left.h_{a b}\right)$ were determined using the original software CromaLabC (Heredia et al., 2004) following the Commission Internationale de L'Eclariage's recommendations (CIE, 2004): the CIE $197610^{\circ}$ Standard Observer and the Standard Illuminant D65.

Euclidean distance between two points in the threedimensional space defined by $L^{*}, a^{*}$ and $b^{*}$ was used for calculating colour differences $\left(\Delta E^{*}{ }_{a b}\right): \Delta E^{*}{ }_{a b}=\left[\left(\Delta L^{*}\right)^{2}+\right.$ $\left.\left(\Delta a^{*}\right)^{2}+\left(\Delta b^{*}\right)^{2}\right]^{1 / 2}$.

\section{HPLC-DAD analysis of phenolic compounds}

An Agilent 1100 chromatographic system equipped with a quaternary pump, an UV-Vis diode-array detector, an automatic injector and ChemStation software (Palo Alto, CA, USA) was used to carry out the HPLC separation, identification and quantification of phenolic compounds. Prior to direct injection, the samples were filtered through a $0.45-\mu \mathrm{m}$ Nylon filter (E0034, Analisis Vinicos, Tomelloso, Spain). All analyses were made in triplicate. Anthocyanin identification was carried out following the method proposed by Heredia et al. (2010). Anthocyanins were separated using a Zorbax C18 column $(250 \times 4.6 \mathrm{~mm}, 5 \mu \mathrm{m}$ particle size $)$ maintained at $38{ }^{\circ} \mathrm{C}$. Acetonitrile-formic acid-water $(3: 10: 87)$ as solvent $\mathrm{A}$ and acetonitrile-formic acid-water (50:10:40) as solvent B were used. The elution profile was as follows: 0-10 $\min 94 \%$ A-6\% B; 10-15 $\min 70 \%$ A-30\% B; 15$25 \min 60 \% \mathrm{~A}-40 \% \mathrm{~B} ; 25-35 \min 55 \% \mathrm{~A}-45 \% \mathrm{~B} ; 35-$ $40 \min 50 \%$ A-50\% B; 40-42 min 40\% A-60\% B; $42-$ $43 \mathrm{~min} 94 \% \quad \mathrm{~A}-6 \%$ B. The flow rate was set at $0.8 \mathrm{~mL} \mathrm{m^{-1 }}$, and the injection volume was $50 \mu \mathrm{L}$. UV-Vis spectra were recorded from 200 to $800 \mathrm{~nm}$ with a bandwidth of $2.0 \mathrm{~nm}$. The quantification was made at $525 \mathrm{~nm}$ by comparing the areas and the retention times with the malvidin 3-glucoside standard (purchased from Extrasynthese, Genay, France). The method used for the HPLC determination of the phenolic compounds was previously carried out by Hernanz et al. (2007). The quantification was made at $280 \mathrm{~nm}$ (benzoic acids, tyrosol and flavan-3-ols), $320 \mathrm{~nm}$ (hydroxycinnamic acid derivatives) and $360 \mathrm{~nm}$ (flavonols), by comparing the areas and the retention times with standards of gallic, protocatechuic and $p$-hydroxybenzoic acids; catechin, epicatechin and tyrosol; caffeic, $p$-coumaric, $m$-coumaric and ferulic acids; and rutin, quercetin, kaempferol and quercetin-3- $D$-galactoside, respectively. For the identification of quercetin derivatives and the hydroxycinnamic acid derivatives, their spectra were compared to those from quercetin and the corresponding free acids, respectively. Phenolic compounds concentration was expressed as milligram per litre. Total anthocyanins, flavonols and flavan-3-ols were calculated as the sum of individual phenolic compounds identified by HPLC. Folin-Ciocalteau reagent was used for the analysis of total polyphenolics (Singleton \& Rossi, 1965).

\section{Statistical analysis}

Statistical analysis was carried out using Statistica version 8.0 software (Statistica, 2007). Univariate analysis of variance (Tukey's test) was applied to discriminate among the means of chemical data and by pairs of traditional wines and wines with a short time and a long time of cold maceration for each studied point. Moreover, multivariate analysis of data (linear discriminant analysis, LDA) was performed to classify the wine samples.

\section{Results and discussion}

The effect of the length of cold maceration on the colour (by tristimulus colorimetry), differential colorimetry and phenolic composition of Syrah red wines elaborated in warm climate has been studied. The study of the changes of those parameters along the winemaking process could be useful to establish the moment, from which cryomaceration shows the optimal results. Therefore, several crucial points and an exhaustive follow-up of the time evolution of the wines have been studied: at the beginning of alcoholic fermentation (AF), after skin removal stage (R) and at different moments of the vinification process of the wine $(10,30,45,60,75,90$ and 120 days).

\section{Conventional analytical data}

The general composition of traditional macerated wines (TM) and cold macerated wines during a short and a long time (SCM and LCM) was analysed in fermented wines. The $\mathrm{pH}$ values and total acidity were similar $(3.2$ and $4.5 \mathrm{~g} \mathrm{~L}^{-1}$ as tartaric acid, respectively) for all wines. Volatile acidity values were around $0.8 \mathrm{~g} \mathrm{~L}^{-1}$ (expressed as acetic acid), being below the limit established by EU (1.2 $\left.\mathrm{g} \mathrm{L}^{-1}\right)$. Moreover, the values of malic acid evidenced the correct development of the malolactic fermentation (malic acid $<0.1 \mathrm{~g} \mathrm{~L}^{-1}$ ). In addition, adequate values of free and total $\mathrm{SO}_{2}$ were obtained for each type of wine (around 25 and $50 \mathrm{mg} \mathrm{L}^{-1}$ of free and total $\mathrm{SO}_{2}$, respectively). The values of alcoholic strength of all wines were around $12.5^{\circ}$ (\% vol.).

\section{Evolution of polyphenolic compounds}

Several types of polyphenolic compounds were identified in all the studied wines, well-known compounds usually present in wine: anthocyanins (including nonacylated, acetylated and $p$-coumaroylated derivatives of the five 
expected anthocyanidins: delphinidin, cyanidin, petunidin, peonidin and malvidin), benzoic acid and hydroxycinnamic acid derivatives, flavan-3-ols and flavonols (Table S1).

Figure S1 shows the evolution of total polyphenols and anthocyanins of wines during the vinification. As can be observed, regardless of the technique used, all types of wines showed a similar pattern evolution of total phenolics, with a notable increase from the alcoholic fermentation to the first stages after barrelling (day 30) (Fig. S1a). After that point, the content of total polyphenols remained more or less constant until the fourth month of vinification (day 120), being significantly higher in comparison with TM when long time of cold maceration was applied (Ortega-Heras et al., 2012). That fact is also observed in Table S1, when the average of the content of individual phenolic compounds during the evolution time (days 10-120) is calculated (TM/LCM). These results were in agreement with those found by other authors (Gordillo et al., 2010; Ortega-Heras et al., 2012) in Tempranillo and Mencía red wines. A diverse behaviour was observed with regard to the evolution of the total anthocyanins during the vinification, being significantly different depending on the technique applied (Fig. S1b). Thus, although a significant $(P<0.05)$ higher content of anthocyanins was observed after alcoholic fermentation in LCM (due to a longer contact with the skins), the three types of wines showed similar trend until the day 60. However, henceforth different pattern evolution was observed. On the one hand, the content of total anthocyanins almost did not change in both cold macerated wines (short and long time) over the time. However, on the other hand, the content of total anthocyanins drastically decreased when cold maceration was not applied (TM) (Fig. S1b), being significantly $(P<0.05)$ lower compared to cold macerated wines from the third month (day 90). As can be seen in Table S1, significant higher contents of virtually all phenolic compounds families were observed when cold maceration was carried out, regardless of the time of the low-temperature application (Puertas et al., 2013). That is the case of benzoic acid derivatives (phenolic acids) and other noncoloured phenolics such as flavan-3-ols and flavonols. This fact is in agreement with Gordillo et al. (2010) when cryomaceration was applied to Tempranillo red wines elaborated in a warm climate, and with GilMuñoz et al. (2009) in Syrah and Cabernet Sauvignon wines, among others. That increase stems from the fact that dry ice produces cellular breakdowns by the freezing of the grape skins, favouring the releasing and solubilisation of the pigments (Zamora, 2003).

With regard to the individual phenolics, significant differences were observed when cryomaceration was applied, regardless of the application time of low temperatures: particularly, some anthocyanins (above all, petunidin derivatives, peonidin-p-coumaroyl-3-glucoside and cyanidin-3-glucoside), gallic acid, ferulic, flavan-3-ols $((+)$-catechin and (-)-epicatechin) and kaempferol. The qualitative differences increased when TM wines were compared with LCM, being, apart from the aforementioned compounds, almost all anthocyanins and some hydroxycinnamic acid derivatives ( $p$-coumaric 1 and 4 derivatives and $m$-coutaric acid). Moreover, the main differences observed when a longer contact time was submitted were mainly due to anthocyanins, gallic acid and some flavonols such as quercetin 1 derivative and kaempferol (SCM/LCM).

\section{Colour evolution}

The evolution of the CIELAB colour parameters $\left(L^{*}, C^{*}{ }_{a b}\right.$ and $\left.h_{a b}\right)$ along the vinification process for each type of wine studied (TM, SCM and LCM) was evaluated (Fig. 1). The pattern evolution of lightness, chroma and hue was similar for the three types of wines. A diminution of the lightness values was observed in all assays (around 4-10\%) after the second month (day 45-60), being more remarkable in the case of TM (Fig. 1). With regard to chroma, notable decreases were observed until 60 days, above all in the case of SCM (the diminution reached the 50\%). However, after that moment, a contrary tendency was observed and increases around 35-45\% occurred until the day 120. Moreover, the values of hue showed upward trends and towards positive values along time evolution in all three types of wines [around $12^{\circ}$ in $\mathrm{CM}$ and even more in TM $\left.\left(17^{\circ}\right)\right]$. This fact was in agreement with Negueruela et al. (1995), who affirmed that negative $b^{*}$ values correspond with a more bluish colours region, being related to young wines. To check the statistical differences of the colour in each point of the vinification stages, Tukey's test $(P<0.05)$ was applied by pairs of samples. Thus, when the three types of wines were compared in each moment, the main statistical differences were mainly observed along time evolution. LCM was the wines with a significant highest chromatic intensity (chroma) and lowest values of lightness and hue in each point (Tukey's test, $P<0.05$ ), being the latter significant only until the 2 months after removal of solid parts. As a consequence, LCM had a higher chromatic intensity, and they were darker and more bluish when compared to TM and SCM, a fact that could be related to the higher amounts of bluish forms of anthocyanins (glucosides and 3-acetyl-glucosides) (Heredia et al., 1998). This fact could be clearly shown in the $\left(a^{*} b^{*}\right)$-colour diagram (Fig. 2). The different location of the LCM, on the one side, and SCM and TM, on the other side, permits to establish objectively the chromatic characteristics of the wines. As can be seen, LCM wines were located in the four quadrant (positive values of $a^{*}$ and 

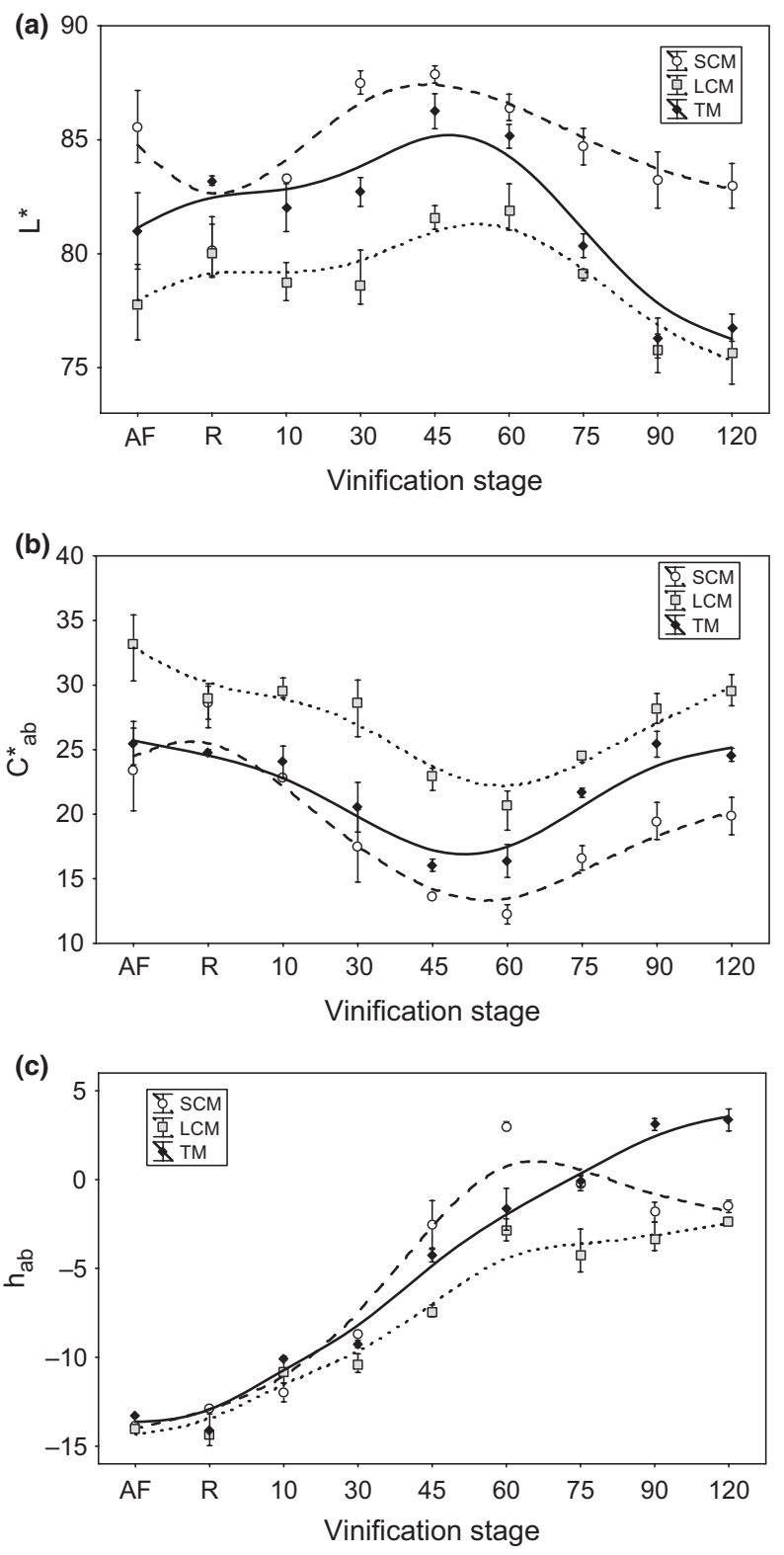

Figure 1 Evolution of CIELAB parameters during vinification of traditional macerated (TM), short cold macerated (SCM) and long cold macerated (LCM) wines: (a) $L^{*}$, (b) $C^{*}{ }_{a b}$ and (c) $h_{a b}$.

negative values of $b^{*}$ ), whereas TM and SCM were mixed and situated between the first and four quadrant (positive values of $a^{*}$ and positive and negative values of $\left.b^{*}\right)$. According to that, LCM wines had a more purple or red-bluish colour than the rest of the samples. These differences were significant, according to Tukey's test $(P<0.05)$ applied by pairs on $a^{*}$ and $b^{*}$ (data not shown). Therefore, the cold maceration during a longer time provoked a positive effect not

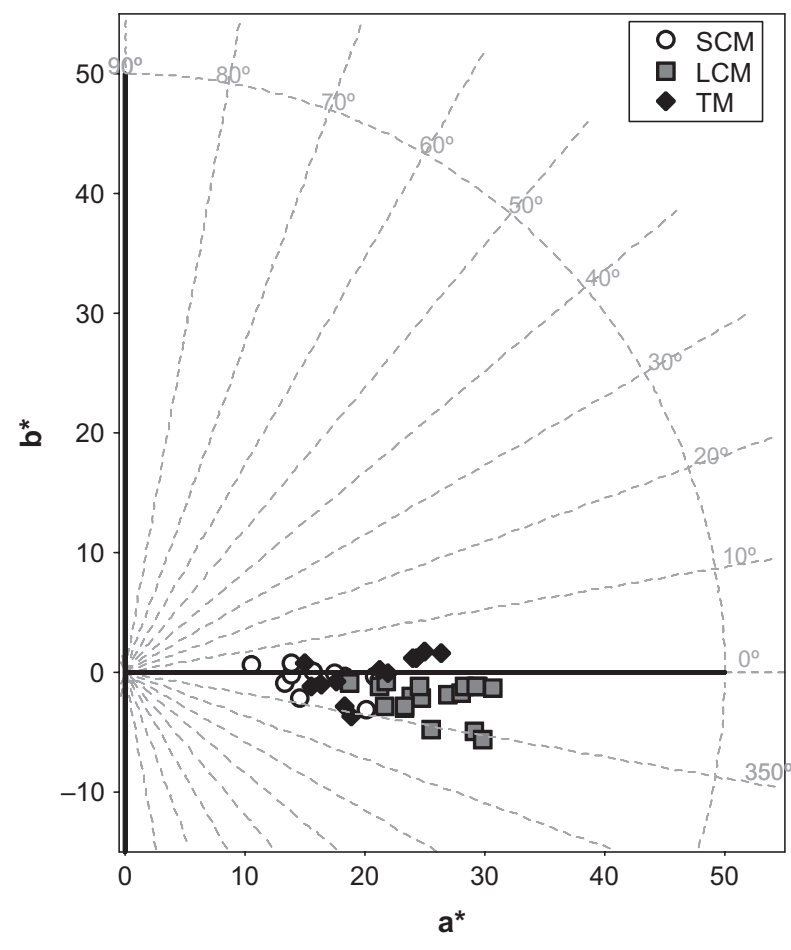

Figure $2\left(\mathrm{a}^{*} \mathrm{~b}^{*}\right)$-plane of CIELAB colour space for traditional macerated (TM), short cold macerated (SCM) and long cold macerated (LCM) wines during the evolution over the time.

only on the colour density (chroma) but also on the colour stability since chroma remains almost constant over the time.

On the basis of previous works about cryomaceration in a warm climate (Gómez-Míguez \& Heredia, 2004; Gordillo et al., 2010), wines conventionally elaborated would be expected to have lower chromaticity and higher lightness than cold macerated wines. In this sense, it could be logical to think that longer cold maceration time (remaining constant other factors such as temperature), higher values of chroma and lower lightness are expected to obtain. However, this fact was not the case of our Syrah wines elaborated in a warm climate, because $C^{*}{ }_{a b}$ of $\mathrm{SM}$ was significantly lower relative to TM, and even more to LCM. Therefore, the use of a short time of cold maceration could provoke a significant decrease in the colour stabilisation, so this technique must be carefully employed.

To evaluate the colorimetric implications of the cold maceration and the influence of the contact time, the mean colour difference $\left(\Delta E^{*}{ }_{a b}\right)$ among pairs of wines during the time evolution was calculated. The mean colour differences $\left(\Delta E^{*}{ }_{a b}\right)$ by pairs of wines (TM/SCM; TM/LCM; SCM/LCM) were up to three CIELAB units, so colour differences were noticeable by the human eyes (Martínez et al., 2001) (data not shown). 
Similar results were obtained by Puertas et al. (2013) in Tempranillo red wines. Visual perception differences among the two assays of cold maceration (SCM/LCM) remained constant and high over the time (around 10 CIELAB units), with similar quadratic variations of lightness and chroma, and practically negligible of hue $\left(\% \Delta^{2} L=30-40, \% \Delta^{2} C=60-70, \% \Delta^{2} H=0-2\right)$. From 2 months of time evolution (day 60), SCM was notably and continuously more diverse than TM (increasing $\Delta E^{*}{ }_{a b}$ from 3 to 8 CIELAB units), whereas those differences decreased when LCM was compared with TM (from 8 to 4-5 CIELAB units). Results showed that the colour differences among TM/SCM and TM/LCM in the first 2 months were mainly quantitative $(\%$ $\left.\Delta^{2} L=20-70, \% \Delta^{2} C=30-80\right)$. From that point forward, that fact was maintained when compared TM and SCM $\left(\% \Delta^{2} L=40-60, \% \Delta^{2} C=35-60\right)$, but also qualitative differences were observed between TM and LCM [with high percentage of contribution of hue to the colour differences $\left.\left(\% \Delta^{2} H=20-50\right)\right]$.

\section{Linear discriminant analysis}

To establish the variables that are better discriminated among samples, linear discriminant analysis was applied to the set of data. A forward stepwise LDA was performed to distinguish between the three sample groups (TM, SCM and LCM). Phenolic compounds and colour characteristics were used to analytically distinguish samples and carry out an exploratory tool to uncover unknown trends in the data. To date, those individual phenolic compounds belonged to monomeric anthocyanins, benzoic and hydroxycinnamic acid derivatives, flavan-3-ols and flavonols, and the angular coordinates of the CIELAB space $\left(L^{*}, C^{*}{ }_{a b}\right.$ and $\left.h_{a b}\right)$ were taken into account as discriminant variables. To choose the descriptors that best distinguished the different winemaking techniques, LDA was performed according to Wilks' $\lambda$ statistic. An $F$ statistic is computed from the partial $\lambda$ values, leading to a $P$-level. The maximum discriminatory power corresponds to minimum $P$-level values. With the application of lineal discriminant analysis (and according to $P$-levels and $F$ values), the variables extracted as significant were gallic acid, tyrosol, hydroxycinnamic acid derivatives ( $p$ coumaric 1 derivative, $m$-coumaric acid and fertaric acid), flavonols (kaempferol and the 1 and 4-derivatives of quercetin) and total phenolics. In addition, the colorimetric characteristic of lightness $\left(L^{*}\right)$ was also considered as discriminant function. Therefore, those variables were able to discriminate between the three groups of samples (TM, SCM and LCM) with high levels of significance $(P<0.001)$.

According to the classification functions, the three types of wines were clearly differentiated each other, being $100 \%$ of the samples correctly assigned. More- over, the percentage of prediction was $100 \%$ for all the samples.

As we have previously seen, colorimetric variables give us a valuable information for classifying the samples according to the winemaking technique; therefore, it seems logical that they should emerge as some of the variables with most weight in our discriminant model.

\section{Conclusions}

Despite the content of polyphenolic compounds seems to follow an expected and logical progression (higher values in cold macerated wines and even higher concentration as time contact increase), it was not the case for the colour of wines. Wines with a longer time of cold maceration had a more stable colour, with more redbluish tonalities when compared to the rest of samples. However, a short contact time not only could produce wines with lower colour stability, but it could be even lower than that observed in traditional wines. Therefore, at least in winemaking in warm climates where colour fades, cold maceration must be carefully applied because the consequences on the colour stabilisation could be undesirable. This study could be another step forward to improve the production of high-quality red wines elaborated in a warm climate region.

\section{Acknowledgments}

We are indebted to Consejería de Innovación, Ciencia y Empresa (Junta de Andalucía, Spain) (project P-10AGR-06331) and Ministerio de Ciencia y Tecnología (project AGL2003-02972) for financial support, and Vinícola del Condado winery (Designation of Origin 'Condado de Huelva', Spain) for collaborating with the experiments.

\section{References}

Álvarez, I., Aleixandre, J.L., García, M.J. \& Lizama, V. (2006). Impact of prefermentative maceration on the phenolic and volatile compounds in Monastrell red wines. Analytica Chimica Acta, 563, 109-115.

Boulton, R. (2001). The copigmentation of anthocyanins and its role in the color of red wine: a critical review. American Journal of Enology and Viticulture, 52, 67-87.

Busse-Valverde, N., Gómez-Plaza, E., López-Roca, J.M., Gil-Muñoz, R. \& Bautista-Ortín, A.B. (2011). The extraction of anthocyanins and proanthocyanidins from grapes to wine during fermentative maceration is affected by the enological technique. Journal of Agricultural and Food Chemistry, 59, 5450-5455.

C.I.E. Publication \& 15., . (2004). Colorimetry, 3rd ed. Vienna: Central Bureau of the International Commission on Illumination.

De Santis, D. \& Frangipane, M.T. (2010). Effect of prefermentative cold maceration on the aroma and phenolic profiles of a Merlot red wine. Italian Journal of Food Science, 22, 47-53.

Feuillat, M. (1993). Etude de quelques conditions de cuvaison susceptibles d'augmentner la composition polyphénolique des vins de Pinot noir. Revue des Enologues, 69, 15-18. 
Feuillat, M. (1996). Vinification of Pinot Noir en bourgogne par macération préfermentaire à froid. Revue des Enologues, 82, 29-31.

Gambacorta, G., Antonacci, D., Pati, S. et al. (2011). Influence of winemaking technologies on phenolic composition of Italian red wines. European Food Research and Technology, 233, 1057-1066.

Gil-Muñoz, R., Moreno-Pérez, A., Vila-López, R., FernándezFernández, J.I., Martínez-Cutillas, A. \& Gómez-Plaza, E. (2009). Influence of low temperature prefermentative techniques on chromatic and phenolic characteristics of Syrah and Cabernet Sauvignon wines. European Food Research and Technology, 228, 777-788.

Gómez-Míguez, M. \& Heredia, F.J. (2004). Effect of the maceration technique on the relationships between anthocyanin composition and objective color of Syrah wines. Journal of Agricultural and Food Chemistry, 52, 5117-5123.

Gómez-Míquez, M., González-Miret, M.L. \& Heredia, F.J. (2007). Evolution of colour and anthocyanin composition of Syrah wines elaborated with pre-fermentative cold maceration. Journal of Food Engineering, 79, 271-278.

González-Neves, G., Gil, G., Barreiro, L. \& Favre, G. (2010). Pigment profile of red wines cv. Tannat made with alternative winemaking techniques. Journal of Food Composition and Analysis, 23, $447-454$

González-Neves, G., Gil, G., Favre, G. \& Ferrer, M. (2012). Influence of grape composition and winemaking on the anthocyanin composition of red wines of Tannat. International Journal of Food Science and Technology, 47, 900-909.

Gordillo, B., López-Infante, M.I., Ramírez-Pérez, P., González-Miret, M.L. \& Heredia, F.J. (2010). Influence of prefermentative cold maceration on the color and anthocyanic copigmentation of organic tempranillo wines elaborated in a warm climate. Journal of Agricultural and Food Chemistry, 58, 6797-6803.

Goumy, D., Couasnon, M. \& Seze, O. (1996). Carboxyque Française. France. French-Patent-Application, FR 2731228 A1.

Heatherbell, D., Dicey, M., Goldsworthy, S. \& Vanhanen, L. (1996). Proceedings of Fourth International Symposium on Cool Climate Enology and Viticulture. New York, Geneva: New York State Agricultural Experiment Station.

Heredia, F.J., Francia-Aricha, E.M., Rivas-Gonzalo, J.C., Vicario, I.M. \& Santos-Buelga, C. (1998). Chromatic characterization of anthocyanins from red grapes-I. pH effect. Food Chemistry, 63, 491-498.

Heredia, F.J., Álvarez, C., González-Miret, M.L. \& Ramírez, A. (2004). CromaLab, análisis de color. In: de la Propiedad Intelectual (SE-1052-04).Spain: Seville.

Heredia, F.J., Escudero-Gilete, M.L., Hernanz, D. et al. (2010). Influence of the refrigeration technique on the colour and phenolic composition of syrah red wines obtained by pre-fermentative cold maceration. Food Chemistry, 118, 377-383.

Hernanz, D., Recamales, A.F., González-Miret, M.L., GómezMíguez, M.J., Vicario, I.M. \& Heredia, F.J. (2007). Phenolic composition of white wines with a prefermentative maceration at experimental and industrial scale. Journal of Food Engineering, 80, $327-335$.

López, M.I., Sánchez, M.T., Díaz, A., Ramírez, P. \& Morales, J. (2007). Influence of a deficit irrigation regime during ripening on berry composition in grapevines (Vitis vinifera L.) grown in semi-arid areas. International Journal of Food Sciences and Nutrition, 58, 491-507.

Martínez, J.A., Melgosa, M., Pérez, M.M., Hita, E. \& Negueruela, A.I. (2001). Visual and instrumental color evaluation in red wines. Food Science and Technology International, 7, 439-444.

Monagas, M. \& Bartolomé, B. (2009). Anthocyanins and Anthocyanin-Derived Compounds. New York: Springer Science and Business Media.
Mori, K., Sugaya, S. \& Gemma, H. (2005). Decreased anthocyanin biosynthesis in grape berries grown under elevated night temperature condition. Scientia Horticulturae, 105, 319-330.

Negueruela, A.I., Echávarri, J.F. \& Pérez, M.M. (1995). A study of correlation between oenological colorimetric indexes and CIE colorimetric parameters in red wines. American Journal of Enology and Viticulture, 46, 353-356.

Ortega-Heras, M., Pérez-Magariño, S. \& González-Sanjosé, M.L. (2012). Comparative study of the use of maceration enzymes and cold pre-fermentative maceration on phenolic and anthocyanic composition and colour of a Mencía red wine. LWT-Food Science and Technology, 48, 1-8.

Parenti, A., Spugnoli, P., Calamai, L., Ferrari, S. \& Gori, C. (2004). Effects of cold maceration on red wine quality from Tuscan Sangiovese grape. European Food Research and Technology, 218, 360-366.

Pérez-Lamela, C., García-Falcón, M.S., Simal-Gándara, J. \& Orriols-Fernández, I. (2007). Influence of grape variety, vine system and enological treatments on the colour stability of young red wines. Food Chemistry, 101, 601-606

Puertas, B., Jiménez, M.J., Cantos-Villar, E. \& Piñeiro, Z. (2013). Effect of the dry ice maceration and oak cask fermentation on colour parameters and sensorial evaluation of Tempranillo wines. International Journal of Food Science and Technology, 48, 835-842.

Singleton, V.L. \& Rossi, J.A. (1965). Colorimetry of total phenolics with phosphomolybdic-phosphotungstic acid reagents. American Journal of Enology and Viticulture, 16, 144-158.

Soto-Vázquez, E., Río Segade, S. \& Orriols Fernández, I. (2010). Effect of the winemaking technique on phenolic composition and chromatic characteristics in young red wines. European Food Research and Technology, 231, 789-802.

Statistica (2007). StatSoft Inc. STATISTICA (Data Analysis Software System). Tulsa, OK: Statistica.

UE (2003). Official Methods to Wine Analyses, Reglamento 440/ 2003.

Zamora, F. (2003). Elaboración y crianza del vino tinto. Aspectos cientificos y prácticos. Madrid: AMV.

\section{Supporting Information}

Additional Supporting Information may be found in the online version of this article:

Table S1. Mean concentration $\left(\mathrm{mg} \mathrm{L}^{-1}\right)$ and standard deviations of phenolic compounds in wines with traditional maceration (TM), short cold maceration (SCM) and long cold maceration (LCM) $(n=63)$. The effect of the time of cold maceration by the study of the evolution during time has been considered. Polyphenolic compounds and colorimetric characteristics of two different cold maceration treatments, in comparison with a control wine, have been studied. $\left(a^{*} b^{*}\right)$-plane of CIELAB colour space for the three types of wines during the evolution over the time is reflected in the graphical abstract.

Figure S1. Total polyphenols (a) and total anthocyanins (b) contents evolution during vinification in traditional macerated (TM), short cold macerated (SCM) and long cold macerated (LCM) wines. 